\title{
Massive subcutaneous emphysema from a complicated intubation
}

\author{
Muhammad A Zafar MD ${ }^{1}$, Ali Raza MD², Gaurav Khanna MD ${ }^{1}$
}

\begin{abstract}
A 58-year-old woman with morbid obesity, diabetes and rheumatoid arthritis was admitted to the intensive care unit with septic shock due to an infected knee that required surgical irrigation and drainage. Postoperatively, she developed hypercarbic respiratory failure necessitating emergent reintubation. Three hours later, a tense swelling with crepitus was noticed on her neck and chest. A computed tomography scan of her chest revealed massive subcutaneous emphysema, pneumomediastinum and pneumothorax due to a tracheal laceration (Figures 1 to 3 ). She was emergently taken to the operative room. Flexible bronchoscopy showed a posterior tracheal perforation just above the carina. Right thoracotomy revealed a $2 \mathrm{~cm}$ tear in the membranous trachea extending toward the right main stem bronchus, which was repaired. After a prolonged stay in the intensive care unit, the patient died due to multiorgan failure and gastrointestinal bleeding.
\end{abstract}

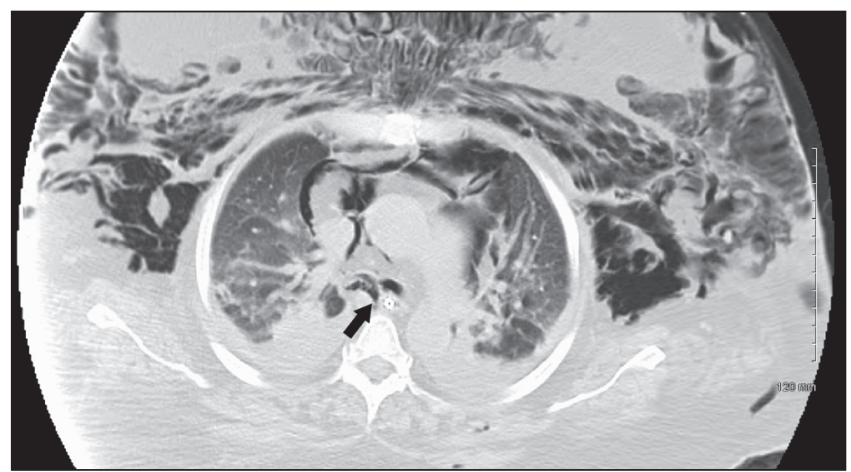

Figure 1) Computed tomography scan showing massive subcutaneous emphysema and pneumomediastinum caused by a complicated endotracheal intubation. The tracheal injury (arrow) is apparent posteriorly near the level of carina proximal to the right main stem bronchus

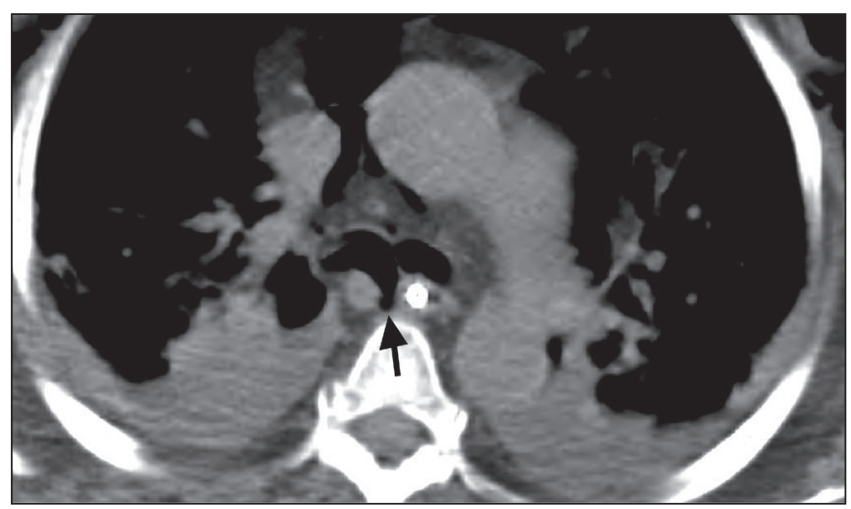

Figure 2) A magnified image of the chest computed tomography scan is shown to demonstrate the site of tracheal injury (arrow)

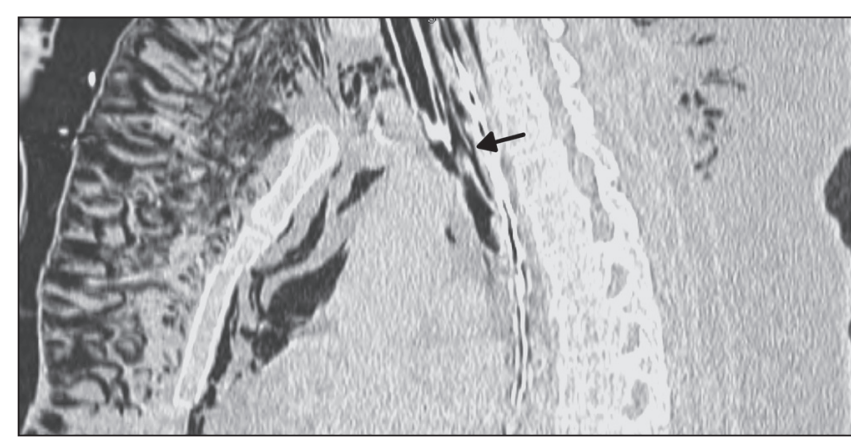

Figure 3) A sagittal section of the chest computed tomography scan shows focal irregularity and discontinuity of the posterior tracheal wall (arrow) near the level of the carina at site of tracheal injury. The distal end of the endotracheal tube is apparent in close proximity to the site of the injury. Pneumomediastinum and extensive subcutaneous emphysema are visible

\section{KEY LEARNING POINTS}

- Tracheal laceration after endotracheal intubation is a rare but life-threatening complication, with a mortality rate as high as $22 \%$ (1). The incidence is $<1 \%$, with a higher prevalence among women of shorter stature and patients $>50$ years of age $(1,2)$. Older age and male sex are associated with increased mortality (1).

- Emergent intubation increases the risk of death from tracheal injury by threefold compared with elective intubation (1).

- Subcutaneous emphysema is the most common finding in tracheal lacerations. It serves as a sentinel sign that stimulates further confirmatory studies to establish the diagnosis. Other signs include mediastinal emphysema, pneumothorax, dyspnea, dysphonia, cough, hemoptysis and pneumoperitoneum (1).

- During emergent intubation, caution should be taken in choosing the correct endotracheal tube size, depth and force of insertion, the use of long introducers and overdistention of the cuff $(1,3)$.

- Management of tracheal laceration may be conservative or surgical based on the location and extent of the injury and patient comorbidities $(1,3)$.

\section{RFEERENCES}

1. Miñambres E, Burón J, Ballesteros MA, Llorca J, Muñoz P,

González-Castro A. Tracheal rupture after endotracheal intubation:

A literature systematic review. Eur J Cardiothorac Surg 2009;35:1056-62.

2. Borasio P, Ardissone F, Chiampo G. Post-intubation tracheal rupture.

A report on ten cases. Eur J Cardiothorac Surg 1997;12:98-100.

3. Carbognani P, Bobbio A, Cattelani L, Internullo E, Caporale D, Rusca M. Management of postintubation membranous tracheal rupture.

Ann Thorac Surg 2004;77:406-9.

The 'Images in Respiratory Medicine' section of the Canadian Respiratory Journal aims to highlight the importance of visual interpretation, whether physiological, radiological, bronchoscopic, surgical/thorascopic or histological, in the diagnosis of chest diseases. Submissions should exemplify a classic, particularly dramatic or intriguing presentation of a disease while offering an important educational message to the reader (insightful diagnostic pearls or differential diagnosis, etc). This section is not intended to be a vehicle for publication of case reports (see the Clinico-Pathologic Conferences for case-based leaning series).

${ }^{1}$ Pulmonary, Critical Care and Sleep Medicine Division, University of Cincinnati College of Medicine, Cincinnati, Ohio; ${ }^{2} \mathrm{Gastroenterology}$ and Hepatology Division, Baylor College of Medicine, Houston, Texas, USA

Correspondence: Dr Muhammad A Zafar, Pulmonary, Critical Care and Sleep Medicine Division, University of Cincinnati College of Medicine, 231 Albert Sabin Way, Cincinnati, Ohio 45229, USA. Telephone 513-827-2345, e-mail zafarmd@ucmail.uc.edu 


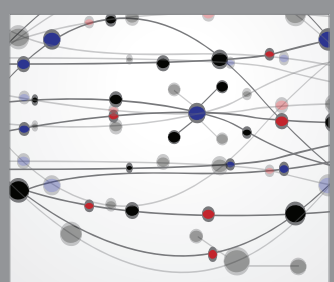

The Scientific World Journal
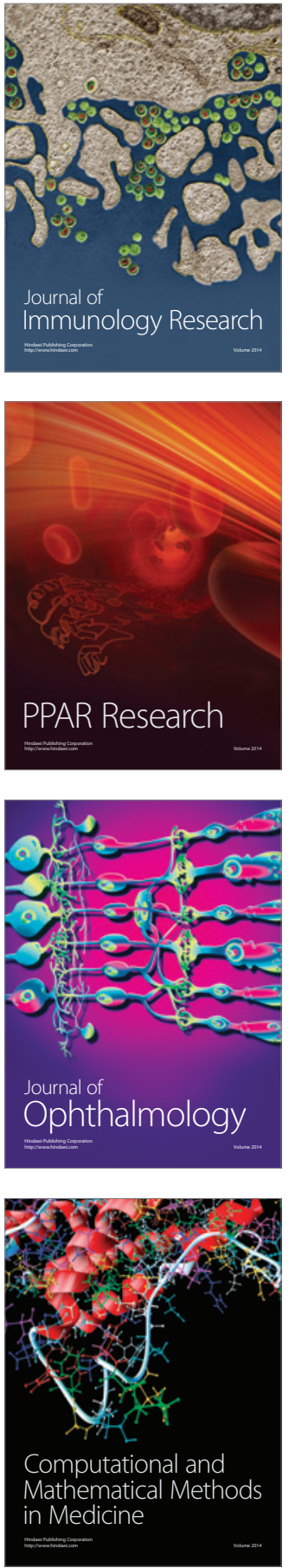

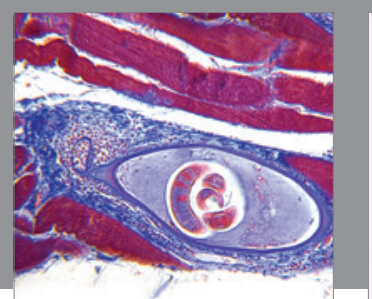

Gastroenterology Research and Practice

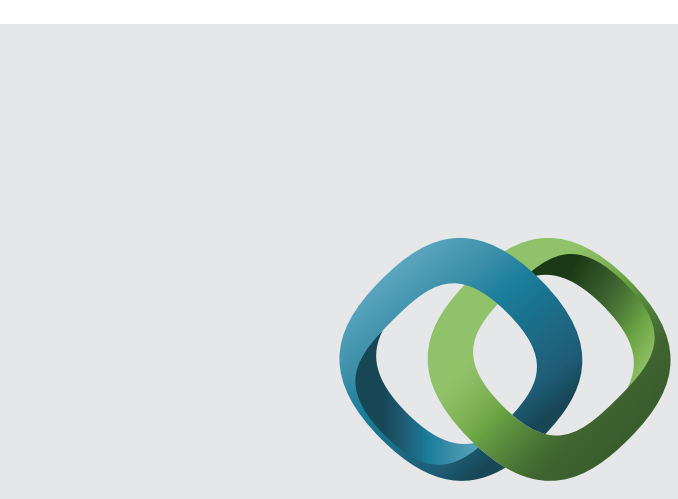

\section{Hindawi}

Submit your manuscripts at

http://www.hindawi.com
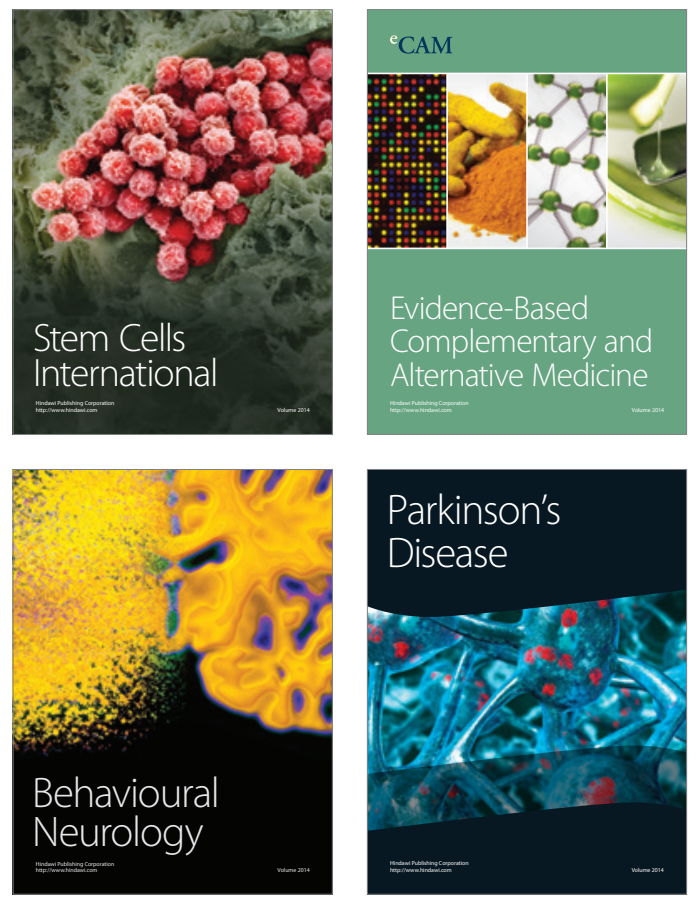
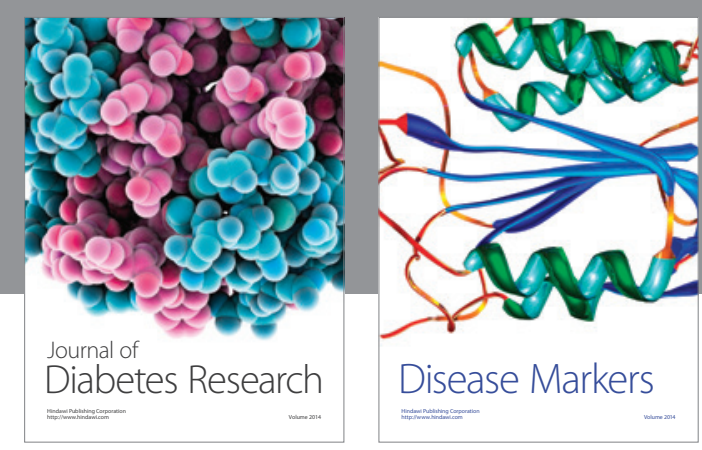

Disease Markers
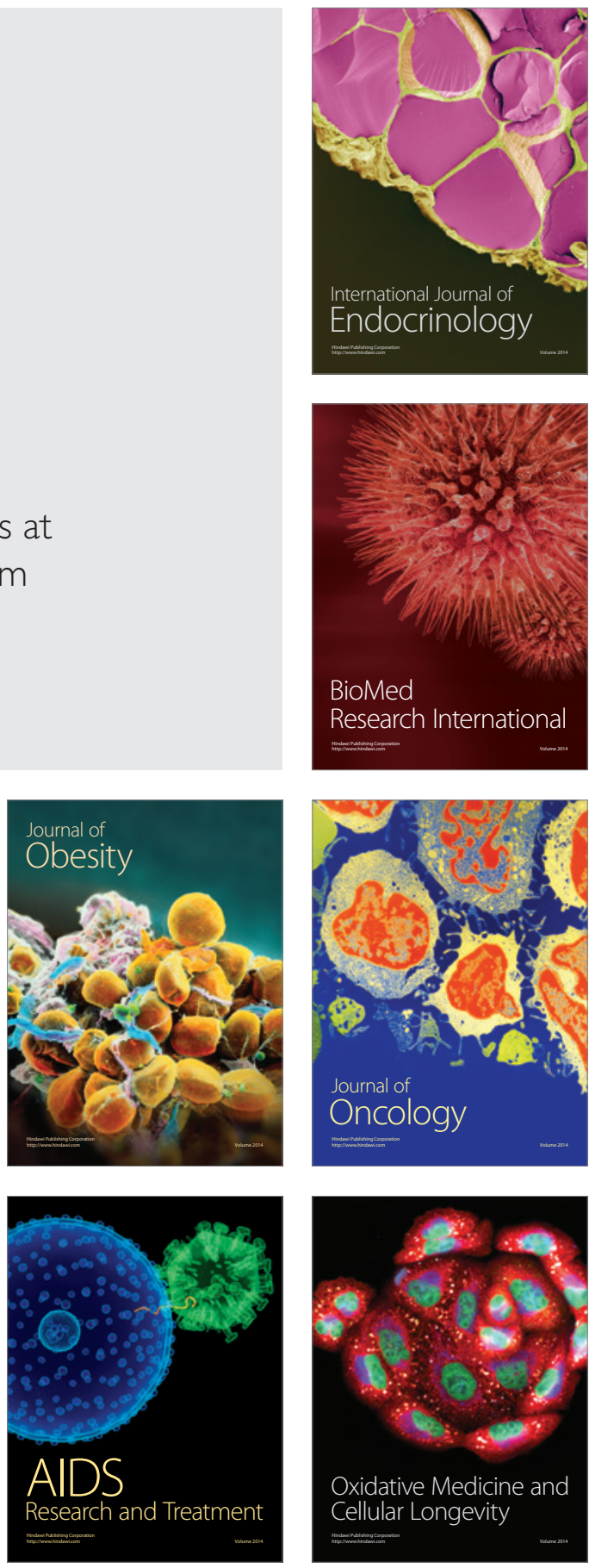